\title{
Osipovs's fire nozzles as a means of combating environmental pollution
}

\author{
Arthur Osipov ${ }^{1, *}$ \\ ${ }^{1}$ Irkutsk National Research Technical University, 83 Lermontov St., Irkutsk, 664074, Russia
}

\begin{abstract}
The classification of the main types of fires is provided, their effect on environmental pollution and adversely affecting people's health is noted. The harmful effect of the consequences of forest fires on the ecology is shown, the main toxic substances released into the atmosphere are given. The harm caused by industrial fires of flammable and combustible liquids is analyzed. The specifics of extinguishing these fires and the need for Osipovs's fire nozzles are substantiated. Design features of Osipovs's fire nozzles are considered. The basics of calculating their tactical and technical characteristics are given. The effectiveness of their practical application in extinguishing forest and industrial fires of oil products is shown. Analytical studies of literary material were conducted. Calculation according empirical formulas and schemes is provided. Polygon and full-scale tests of Osipovs's manual and fire monitors are presented. As a result of theoretical and experimental studies, the design was optimized and the tactics of using these fire nozzles in a fire were developed. The practical application of Osipovs's manual and fire monitors allows get better the working conditions of nozzlemans, increasing fire fighting efficiency, reducing environmental pollution and improving its ecology.
\end{abstract}

Fires - uncontrolled combustion processes, accompanied by the destruction of material values and creating a danger to people's lives [1, 2], are divided into three main groups of forest, industrial and domestic. Regardless of the specifics, all fires to varying degrees pollute the environment and have an adverse effect on human health.

The greatest environmental pollution and harm to human health is caused by forest fires, classified as high, low and underground. The smoke of these fires contains about 175 toxic compounds [3]. It changes the chemical composition of the atmosphere, water and soil, the amount of precipitation, air temperature, natural light of the earth and other parameters of our environment. As a result of forest fires, $20 \%$ of pollutants and aerosols, including carbon oxides and ammonia, enter the planet's atmosphere. Just in the Northern Hemisphere, carbon monoxide emissions are about $11 \cdot 10^{6} \mathrm{t} /$ year, aerosols $(35-360) \cdot 10^{6} \mathrm{t}$ / year, ammonia - up to $12 \cdot 10^{6} \mathrm{t} /$ year [4].

Short-term and long-term consequences are distinguished depending on the time of the impact of forest fires on the environment.

\footnotetext{
*Corresponding author: arthur.osipov@rambler.ru
} 
Short-term and long-term consequences are distinguished depending on the time of the impact of forest fires on the environment.

The first group of consequences of forest fires should include an increase in the temperature of the environment in the combustion zone to $300 \mathrm{~K}$ and higher, while both people and animals who are in the fire zone die

Emissions of chemical compounds harmful to the health of living organisms in the surface layers of the atmosphere, including carbon monoxide and nitrogen oxides. Increasing the density of heat fluxes to $200 \mathrm{~kW} / \mathrm{m}^{2}$, contributing to spontaneous combustion of combustible materials and buildings. Smoke of the surface layer of the atmosphere and the cessation of flights of aircraft and the movement of water and land vehicles. Adverse effects of infrasound waves on people, as well as other negative factors of the fire, for example, burning of oxygen [5, 6].

The second group of adverse consequences of forest fires includes the destruction of valuable tree species and timber

Soil erosion, decreasing river flow, and disruption of existing ecosystems. Decrease in solar radiation on the underlying surface and late ripening of agricultural crops. Global warming due to disruption of the natural carbon cycle. Repeated radioactive contamination of the area in radioactive forests $[5,6]$.

The effects of industrial fires in industry and transport are very unfavorable for the environment, since various toxic compounds can be present in the combustion products, in particular, oxides of carbon, sulfur, nitrogen, hydrogen chloride, hydrocarbons of various classes, alcohols, aldehydes, benzene, and salts and oxides of heavy metals, Benzo[ $a]$ pyrene, dioxides.

The fires of flammable and combustible liquids at oil depots, vehicles, oil refineries, chemical plants, radiation facilities, warehouses of fertilizers, pesticides and hazardous chemicals are especially harmful to the environment.

A specific feature of extinguishing these fires is the inability to supply extinguishing agents from a distance of less than $45 \mathrm{~m}$ due to the large thermal radiation at which the temperature in the combustion zone can increase to $800-1500{ }^{\circ} \mathrm{C}$ at a critical temperature for a person of $70{ }^{\circ} \mathrm{C}$. It should be noted that the range of the jets of modern fire nozzles and foam generators of medium multiplicity when extinguishing flammable and other combustible liquids does not exceed 30-35 m [7].

Design features of manual Osipovs's fire nozzles (RPSO) [8] (Fig. 1), consisting in the execution of their direct-flow part in the form of a confuser-diffuser nozzle with optimal angles of compression and expansion of the flow from the point of view of hydraulic resistance, as well as the presence of other patented components Osipovs's modernized fire monitors (LPSO) [9] (Fig. 2), allow intensively extinguishing a large amount of fire extinguishing substances to a distance of about 45-50 m. At the same time, quick-hardening foams, as well as other substances with improved extinguishing properties due to additives, can be supplied to the quenching.

It should be noted that, unlike the existing fire nozzles in Osipovs's manual fire nozzles and fire monitors, multistage air crushing of the foaming agent occurs, which allows generating air-mechanical foam of not low, but medium expansion and increasing the fire extinguishing ability of the prepared foam, and therefore, reduce the time extinguish the fire and reduce the negative environmental effects.

In addition, it must be said that the productivity of these nozzles, depending on the diameter of the neck of the confuser-diffuser branch pipe, is limited only by the capabilities of the pumping units of the fire fighting equipment used to extinguish the fire. 


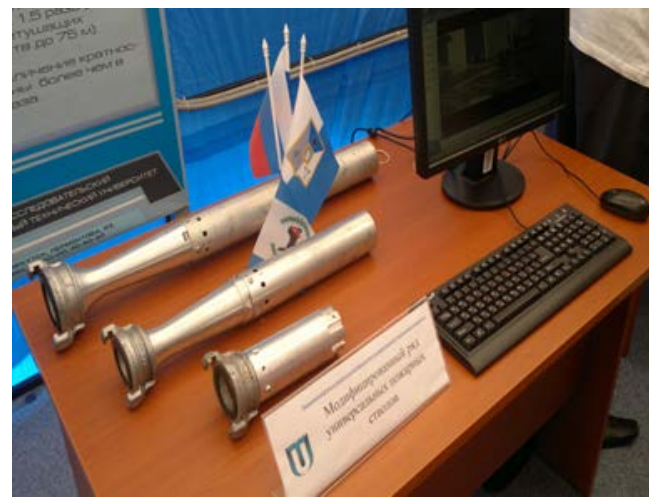

a

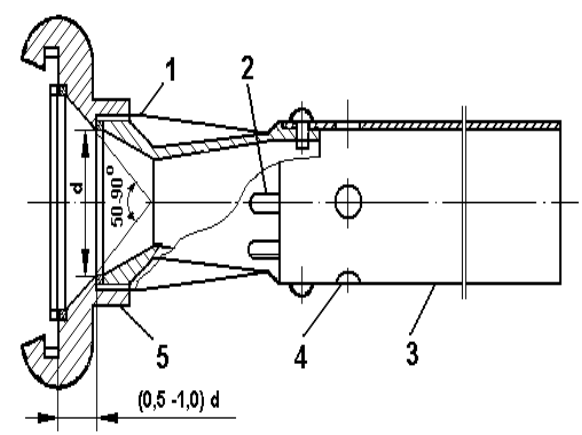

b

Fig. 1. Osipovs's manual fire nozzles: a) - lineup; b) - design: 1 - receiving housing; 2 - recesses on the housing for air intake; 3 - jet forming nozzle; 4 - air holes; 5 - threaded-end discharge coupling head

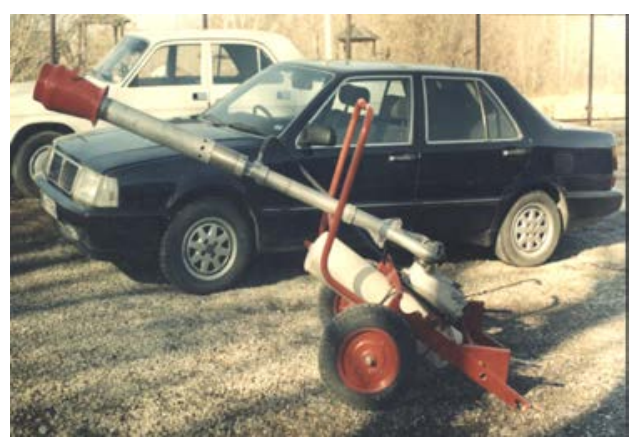

a

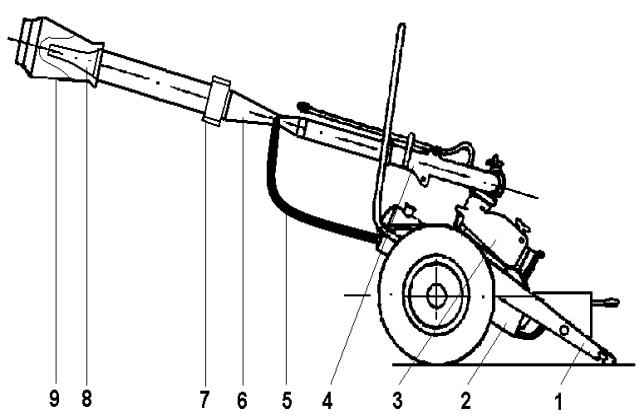

b

Fig. 2. Osipovs's fire monitors: a) - appearance; b) - construction: 1 - mounted or trailed trolley; 2 capacity for hardener or additive; 3 - receiving housing with pressure pipes and a rotary tee; 4 branching with a pipe; 5 - suction sleeve; 6 - water tube with an ejection device; 7 - a movable ring; 8 - removable confuser pipe; 9 - confuser-diffuser deflector

A comparative assessment of the performance characteristics of modern manual fire nozzles can be made according to the data presented in table. 1.

Comparing the characteristics presented in table 1 of manual fire nozzles, it can be noted that the range of American and English barrels is comparable to the range of extinguishing agents delivered by the Osipovs's RPSO-16 construction barrel, but the imported barrels are inferior to this domestic barrel in the amount of foam supplied and its fire extinguishing ability.

High-performance mobile fire engines and stationary fire facilities are equipped with fire monitors, which have higher tactical and technical parameters and larger overall dimensions compared to manual fire nozzles.

At present, portable, transported on trailers and carts, as well as stationary fire monitors are used to extinguish forest and large-scale production fires. 
Table 1. Performance characteristics of manual fire nozzles

\begin{tabular}{|l|c|c|c|c|c|c|}
\hline \multirow{2}{*}{ Parameter } & \multicolumn{7}{|c|}{ manual fire nozzles } \\
\cline { 2 - 7 } & $\begin{array}{c}\text { DELTA } \\
\text { ATTACK- } \\
750\end{array}$ & $\begin{array}{c}\text { DUAL- } \\
\text { FORCE- } \\
\text { RU }\end{array}$ & $\begin{array}{c}\text { HAND- } \\
\text { LIN -RU }\end{array}$ & $\begin{array}{c}\text { MID- } \\
\text { MATIC- } \\
\text { RU }\end{array}$ & $\begin{array}{c}\text { AWG } \\
\text { TSPR } \\
\text { 2950 EN }\end{array}$ & $\begin{array}{c}\text { RPSO - } \\
16^{*}\end{array}$ \\
\hline $\begin{array}{l}\text { 1. Country of } \\
\text { manufacture }\end{array}$ & GB & USA & USA & USA & Germany & Russia \\
\hline $\begin{array}{l}\text { 2. Productivity on } \\
\text { foam, m3 / min }\end{array}$ & - & $2-6$ & $2-15$ & $5-12$ & $8-19$ & $24^{*}$ \\
\hline $\begin{array}{l}\text { 3.Water } \\
\text { consumption, l / s }\end{array}$ & $5-13$ & $5-19$ & $3-22$ & $5-13$ & $9-16$ & 16 \\
\hline 4. Jet range, m & $40-45$ & $45-50$ & $45-50$ & $45-47$ & $15-20$ & $45-50^{*}$ \\
\hline $\begin{array}{l}\text { 5. foam } \\
\text { multiplicity }\end{array}$ & - & $4-6$ & 11 & $13-15$ & $10-15$ & $25^{*}$ \\
\hline $\begin{array}{l}\text { 6.Operating } \\
\text { pressure, bar }\end{array}$ & $5-8$ & $3-7$ & 7 & $5-7$ & 6 & $6-10$ \\
\hline 7. Shut-Off Valve & Pipe & Pipe & Pipe & Pipe & Pipe & - \\
\hline 8. Weight, kg & 2,4 & 3,2 & 3,2 & 2,2 & 3,6 & $1,0-1,5$ \\
\hline
\end{tabular}

According to the characteristics presented below in table. 2, you can analyze the advantages and disadvantages of the best examples of fire monitors.

Table 2. Performance characteristics of fire monitors

\begin{tabular}{|l|c|c|c|c|c|c|}
\hline & \multicolumn{6}{|c|}{ fire monitors } \\
\cline { 2 - 7 } Parameter & $\begin{array}{l}\text { CROSSFI- } \\
\text { RE-RU }\end{array}$ & $\begin{array}{c}\text { BLITZFI- } \\
\text { RE-RU }\end{array}$ & $\begin{array}{c}\text { Mercury } \\
\text { Monitors }\end{array}$ & LS-P20 & $\begin{array}{c}\text { PARTNER } \\
\text { LS-P32U }\end{array}$ & $\begin{array}{c}\text { LPSO- } \\
\text { B30* }\end{array}$ \\
\hline $\begin{array}{l}\text { 1.Country of } \\
\text { manufacture }\end{array}$ & EU & EU & USA & Russia & Russia & Russia \\
\hline $\begin{array}{l}\text { 2.Productivity on } \\
\text { foam, m3 / min }\end{array}$ & - & $1,8-14$ & $13-19$ & $8,5-9,6$ & 13,5 & $45^{*}$ \\
\hline $\begin{array}{l}\text { 3.Water } \\
\text { consumption, l / s }\end{array}$ & $9-80$ & $6-32$ & 31,6 & 20 & 32 & 30 \\
\hline 4. Jet range, m & 70 & $50-60$ & $45-50$ & $50-60$ & $55-60$ & $55-60 *$ \\
\hline $\begin{array}{l}\text { 5. foam } \\
\text { multiplicity }\end{array}$ & - & $5-7$ & $7-10$ & $7-8$ & 7 & $25^{*}$ \\
\hline $\begin{array}{l}\text { 6. Operating } \\
\text { pressure, bar }\end{array}$ & $0,7-1,2$ & $0,4-1,2$ & 0,7 & 0,8 & $0,7-1,6$ & $0,7-1,2$ \\
\hline 7. Shut-Off Valve & Pipe & Pipe & Pipe & Pipe & Pipe & - \\
\hline 8. Weight, kg & 23,3 & 15 & 6,4 & 10 & 9 & 23 without \\
trolley
\end{tabular}

A significant advantage of the Osipovs's fire nozzles, compared with existing manual and fire monitors, is also the ability to receive and supply air-mechanical foam increased to 30 multiplicity units to more than $45 \mathrm{~m}$.

The range of the currently existing air foam fire nozzles does not exceed $30 \mathrm{~m}$, while the multiplicity of the low-multiplicity foam prepared by them is about 7-10 units [10], which significantly reduces the fire fighting effectivity and contributes to environmental pollution.

The advantages of Osipovs's fire nozzles should also include the possibility of their operation in a wide range of extinguishing agents, including quick-hardening foams. The latter, unlike various foaming agents and other surfactants, do not pollute the soil and water, violating the environment, and can be removed mechanically after a fire. Previously, the 
ability of these nozzles to generate medium-multiplicity air-mechanical foam was also noted.

It should be noted that Osipovs's fire monitors have the greatest fire extinguishing ability and effectiveness during stationary installation on various mechanical lifts. At the same time, a significant environmental effect is achieved by reducing the time to extinguish the fire.

In fig. 3a shows a fragment of the working for water of the Osipovs's LPSO-70 fire monitor, which is stationary installed on the AKP-30 auto articulated boom, 3, b extinguishing by this fire monitor of a reservoir with an oil product foam of medium multiplicity.

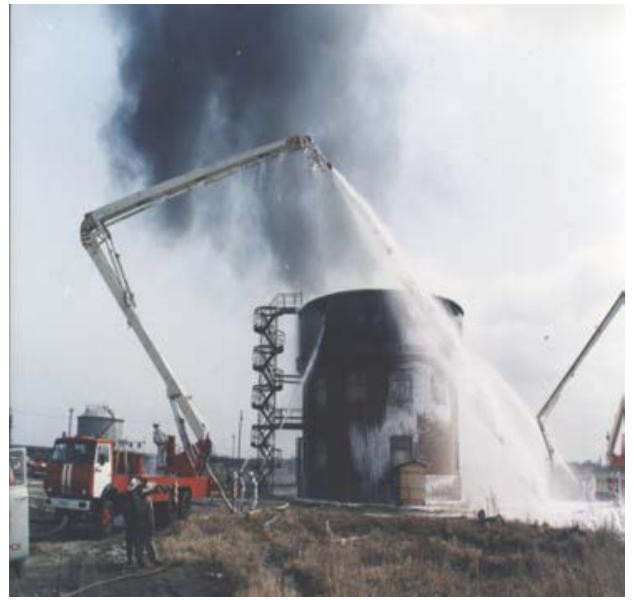

a

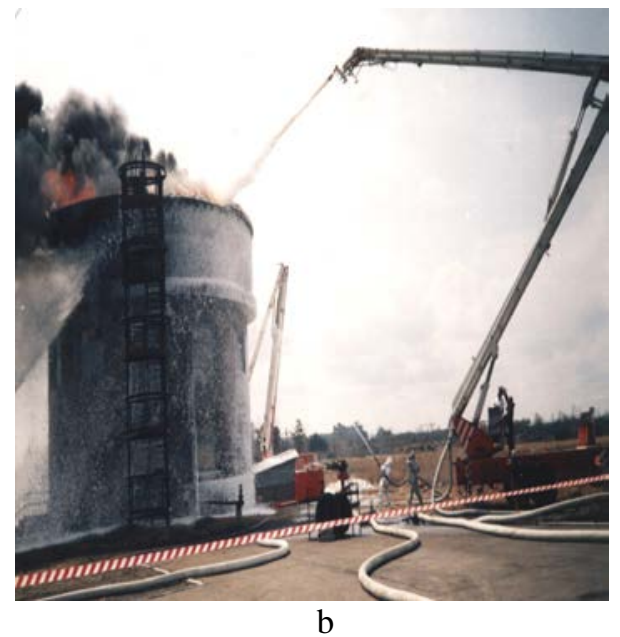

b

Fig. 3. Extinguishing the oil product tank with the Osipovs's fire monitor LPSO-70, stationary installed on the AKP-30 auto articulated boom,: a) - work of the nozzle with water; b) - the work of the nozzle with the medium-multiplicity foam

The field and fire tests of the Osipovs's fire nozzles [11, 12, 13], conducted on the basis of fire rescue units of the Main Directorate of the Ministry of Emergencies of Russia in the Irkutsk Region, made it possible to establish a relationship between the neck diameter of the confuser-diffuser pipe $d$ and the tactical and technical parameters of the trunks, and also to propose the following empirical dependencies to determine their productivity $Q$, fire extinguishing area $S$ and the range of the fire extinguishing jet $L$ :

$$
\begin{gathered}
Q=6,35^{-2} d^{2}, l \cdot \mathrm{c}^{-1} ; \\
S=0,89^{-2} \mathrm{~d}^{2}, \mathrm{~m}^{2} \\
L=1,13 \mathrm{~d}, \mathrm{~m} .
\end{gathered}
$$

In fig. 4a shows a graphical dependence of the fire extinguishing area $\mathrm{S}\left(\mathrm{m}^{2} 10^{3}\right)$ on the neck diameter of the confuser-diffuser pipe, in Fig. $4 \mathrm{~b}$ - dependence of the range L (m) of the supply of extinguishing jets formed by the Osipovs's fire nozzles.

The effectiveness of extinguishing forest and industrial fires of petroleum products, and consequently, the effectiveness of the fight against environmental pollution through the use of Osipovs's manual and fire monitors, has been confirmed in practice. 
In fig. 5 presents fragments of the field tests of Osipovs's manual fire nozzles during their work for water and air-mechanical medium-multiplicity foam. It should be noted that the air-mechanical foam prepared by the currently existing watering nozzles has a multiplicity, as noted earlier, of no higher than 7-10 units, and refers to the category of lowmultiplicity foams having a low fire extinguishing ability.

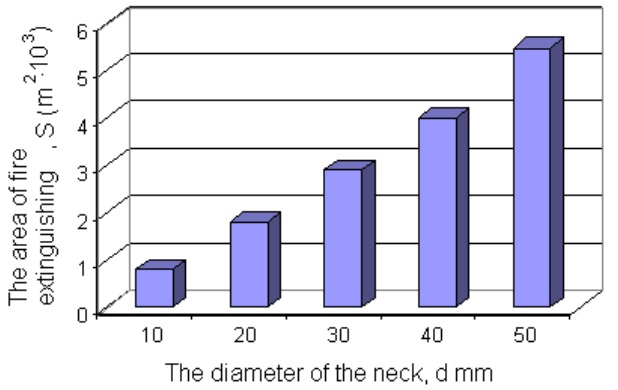

a

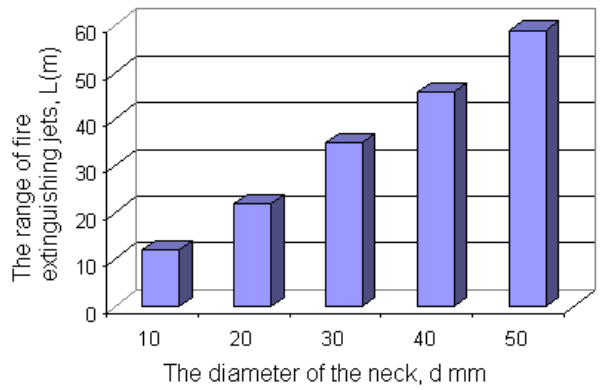

$\mathrm{b}$

Fig. 4. The effect of the diameter of the neck of the confuser-diffuser branch pipe of Osipovs's fire nozzles: a) on the area of fire extinguishing; b) — on the range of fire extinguishing jets

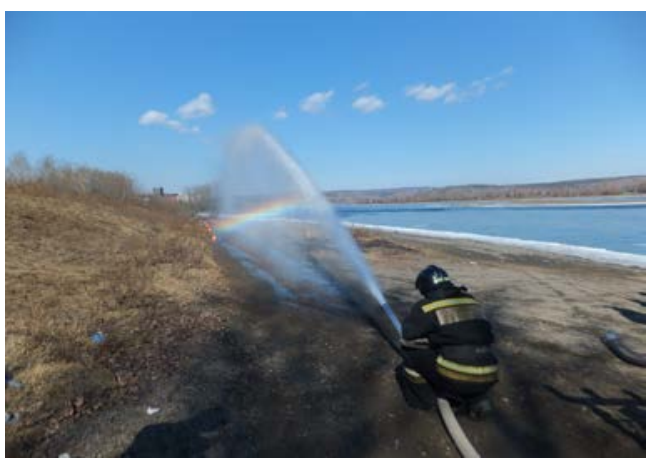

a

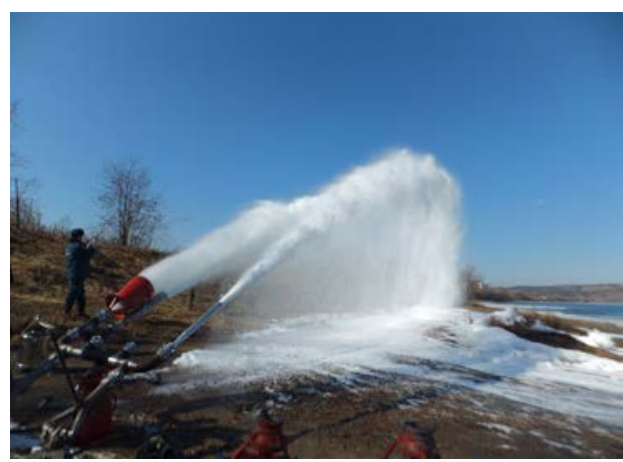

b

Fig. 5. Polygon tests of the Osipovs's RPSO-16 manual fire nozzle: a) - fire nozzle work for water; b) - the work of the barrel on the foam (jet on the right) in comparison with the work of a standard foam generator GPS-600 (jet on the left)

In fig.6 shows a fragment of the field tests of Osipovs's fire monitor LPSO-70. The oil product was extinguished from the ground when the nozzle generated air mechanical medium-multiplicity foam.

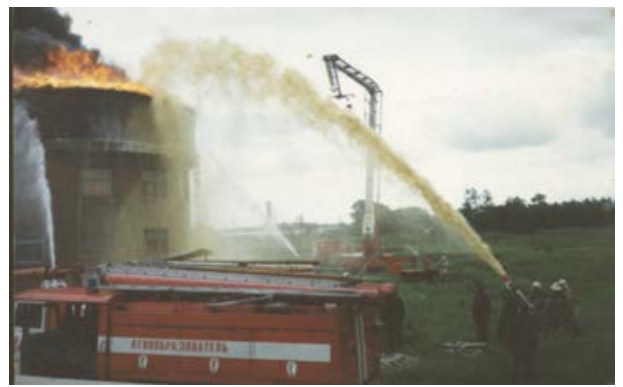

Fig. 6. Field fire tests of Osipovs's fire monitor LPSO-70 working from the ground 
Thus, thanks to the Osipovs's manual and fire monitors, it is possible to supply large quantities of fire extinguishing substances, which depend only on the performance of the pumping units of modern fire engines, from a safe distance for the nozzle man, about 45-50 $\mathrm{m}$, to effectively extinguish fire at the same name reducing environmental pollution.

\section{Conclusion}

Because Osipovs's manual fire nozzles and fire monitors presented in this work allow for the safe operation of nozzleman, increase the efficiency of extinguishing fires by increasing the intensity of the supply of extinguishing agents and improving their fire extinguishing ability, the appropriateness of their practical application in a difficult operational environment when fighting forest and open large industrial fires is not doubtful. In this case, there is a real opportunity to reduce the time to eliminate these fires and reduce the level of environmental pollution.

\section{References}

1. What is a fire. The main factors of the fire. Causes of Fire. https://01.pф/articles/o_pozhare/chto_takoe_pozhar_osnovnye_faktory_pozhara_prichi ny_vozniknoveniya_pozharov/

2. Types of fires. Fire classification. Fire prevention. https://businessman.ru/new-vidypozharov.html

3. A.G. Osipov, Yu.N. Gornov, P.V. Korolev, Multi-purpose fire nozzles for extinguishing forestry facilities in the Irkutsk region// Vestnik IrSTU. № 6. - Irkutsk, - pp. 48-52 (2010)

4. V.A. Isidorov, Organic chemistry of atmosphere. ( Khimiya, Leningrad. 1969).

5. The danger factors of fire for people and material values. https://studme.org/1236040928366/bzhd/opasnost_negativnyh_faktorov_pozharov_dly a_lyudey_materialnyh_tsennostey

6. Forest fire and ecology. http://www.dishisvobodno.ru/lesnye-pozhary-i-ix-vliyanie-naekologiyu.html

7. A.G. Osipov, Calculation-theoretical and practical research multi-purpose Fire nozzle Osipovs. Vestnik IrSTU [Irkutsk State Technical University], no. 3(22), pp. 44-53 (2018)

8. A.G. Osipov [et. al.]. Fire nozzle Osipovs. Patent RF, no. 97102129/12, (1997)

9. A.G. Osipov [et. al.]. Multi-purpose fire nozzles. Patent RF, no. 2008130703/22, (2008)

10. A.G. Osipov, Yu.N. Gornov, Improving manual multi-purpose fire hose design. Vestnik IrSTU [Irkutsk State Technical University], no. 4, pp. 66-70 (2013)

11. A.G. Osipov, M.R. Bagautdinov, Improving ergonomic characteristics manual multipurpose fire nozzle design. [Mechanical engineering and transport of Siberia]. Materials of All-Russia young Conference. Irkutsk, pp. 242-245 (2016)

12. A.G. Osipov, M.A. Savina, Putting out of open large-scale fares in Irkutsk region. Youth vestnik IrSTU [Irkutsk State Technical University], no. 2(9), pp. 18-23 (2019)

13. Yu.N. Gornov, M.R. Bagautdinov, Improving effectiveness extinguishing of aeroplane. [Mechanical engineering and transport of Siberia]. Materials of All-Russia young Conference. Irkutsk, pp. 191-195 (2016) 